Jurnal Media Analis Kesehatan, Vol. 8, No.2, November 2017

http://journal.poltekkes-mks.ac.id/ojs2/index.php/mediaanalis

e-ISSN : 2621-9557

p-ISSN : 2087-1333

\title{
UJI EFEK ANTIBAKTERI EKSTRAK DAUN WUNGU (Graptophylum pictum Griff) ASAL KABUPATEN ENREKANG TERHADAP PERTUMBUHAN Streptococcus mutans
}

\author{
Rahman \\ Jurusan Analis Kesehatan Poltekkes Makassar \\ Koresponden: ramangcarallang@gmail.com
}

\begin{abstract}
ABSTRAK
Penelitian ini bertujuan untuk mengetahui efek antib akteri ekstrak Daun Wungu (Graptophylum pictum Griff) asal Kabupaten Enrekang terhadap pertumbuhan Streptococcus mutans. Jenis penelitian yang digunakan adalah penelitian eksperimental laboratorium. Sampel yang digunakan dalam penelitian ini adalah daun Wungu yang bereasal dari Kabupaten Enrekang dan dibuat dalam bentuk ekstrak berbagai variasi konsentrasi yaitu 2\%, 3\%, 4\%, dan 5\%, serta kontrol positif yaitu Amoxisilin. Hasil penelitian menunjukkan bahwa daun Wungu asal Kabupaten Enrekang memiliki kemampuan menghambat pertumbuhan Streptococcus mutans. Dimana zona hambatan rata -rata untuk $2 \%$ yaitu $12,60 \mathrm{~mm}$, $3 \%$ yaitu $13,73 \mathrm{~mm}, 4 \%$ yaitu $14,82 \mathrm{~mm}$ dan untuk $5 \%$ yaitu $16,10 \mathrm{~mm}$. Untuk pembanding kontrol positif sebesar $17,70 \mathrm{~mm}$ dan kontrol negatif didapatkan $0 \mathrm{~mm}$. Hasil uji statistik memperlihatkan adanya perbedaan yang nyata antara perlakuan dalam menghambat pertumbuhan Streptococcus mutans, dimana $\mathrm{Fh}=366,20$ lebih besar dari pada Ft untuk 0,05 = 3,11 dan 0,01 = 5,06.
\end{abstract}

Kata Kunci : Ekstrak, Daun Wungu, Kab Enrekang,Streptococcus Mutans.

\section{PENDAHULUAN}

Salah satu mikroorganisme yang dapat menimbulkan penyakit yaitu Streptococcus mutans. Bakteri ini termasuk kelompok Streptococcus viridans yang merupakan anggota floral normal rongga mulut yang memiliki sifat $\alpha$-hemolitik dan komensal oportunistik (Jawetz, dkk, 2008). Penyakit yang disebabkan oleh Streptococcus mutans adalah karies gigi. Karies gigi adalah sebuah penyakit infeksi yang merusak struktur gigi. Penyakit ini menyebabkan gigi berlubang. Terjadinya karies didukung oleh adanya proses demineralisasi pada email dan bahkan juga adanya pembentukan plak gigi. Adanya karies pada gigi merupakan salah satu penyebab timbulnya bau mulut (halitosis) (Lailatul Iftitah,2005).

Streptococcus mutans merupakan bakteri gram positif berbentuk bulat yang secara khas membentuk pasangan atau rantai selama masa pertumbuhannya. Streptococcus mutans adalah salah satu bakteri yang mempunyai peranan penting pada pembentukan karies gigi dan halitosis (bau mulut). Bakteri ini tumbuh secara optimal pada suhu sekitar $18^{\circ} \mathrm{C}-40^{\circ} \mathrm{C}$. Streptococcus mutans biasanya ditemukan pada rongga gigi manusia yang lukadan menjadi bakteri yang paling kondusif 
menyebabkan karies untuk email gigi (Lailatul Iftitah,2005; Jawetz dkk, 1996).

Timbulnya karies gigi yang disebabkan oleh Streptococcus mutans dapat dicegah dengan memelihara kebersihan rongga mulut baik secara kimiawi ataupun mekanis. Cara kimiawi dengan menggunakan bahan antibakteri, sedangkan secara mekanis dengan menyikat gigi menggunakan sikat gigi dan pasta gigi yang mengandung antibakteri. Fluoride sebagai bahan antikaries untuk mengkontrol karies gigi yang disebabkan oleh bakteri Streptococcus mutans dan triclosan merupakan bahan kimia non ionik dari golongan bisphenol sintetis yang memiliki sifat antibakteri dan dapat menghambat pertumbuhan bakteri gram positif seperti Streptococcus mutans (Herijulianti, E., dkk, 2010). Tetapi jika fluoride dan bahan antibakteri seperti triclosan ditingkatkan untuk menambah daya antibakteri pada pasta gigi akan menimbulkan resiko fluorosis, toksisitas, demineralisasi gigi, dan perubahan warna email, sehingga diperlukan pilihan alternatif bahan antibakteri yang lebih aman yaitu menggunakan bahan herbal (Bronckers dkk, 2009).

Penggunaaan bahan herbal memiliki keuntungan yaitu mudah didapat, murah, aman dan tidak membahayakan lingkungan sekitar. Salah satu bahan herbal yang terdapat disekitar masyarakat memiliki sifat antibakteri yaitu daun wungu. Tanaman ungu atau disebut pula tanaman wungu memiliki nama latin Graptophyllum pictum adalah tanaman herbal yang biasa digunakan untuk mengatasi masalah kewanitaan, selain itu juga mampu berkhasiat mengobati berbagai penyakit (Wijaya kusuma et al. 1996; Hariana 2009). Tanaman daun wungu mengandung tanin, alkaloid sitosterol, glikosid, flavonoid, steroid, saponin, kalsium oksalat dan asam format. Dengan berbagai kandungan kimiawinya daun wungu mempunyai sifat sebagai obat wasir, laksatif lemah diuretik ringan. Pada pengobatan tradisional daun wungu juga digunakan untuk pengobatan terhadap luka, bengkak, borok, bisul, penyakit kulit, secara eksperimental ekstrak daun wungu berkhasiat menghambat pembengkakan dan menurunkan permiabilitas vaskular, antiplak gigi / karies gigi, antiinflamasi (Sumarny R., 2013 ;Puspati S., 2013).

Hasil penelitian yang pernah dilakukan oleh Yuvanti tahun 2015 mengemukakan bahwa daun wungu (Graptophylum pictum Griff) mampu memberi efek sebagai antibakteri dalam menghambat pertumbuhan Staphylococcus aureus dan Escherichia coli dan disisi lain daun wungu juga berperan sebagai antijamur dalam menghambat pertumbuhan Candida albicans penyebab keputihan. Penelitian ini bertujuan untuk mengetahui dan menentukan efek antibakteri ekstrak Daun Wungu asal Kabupaten Enrekang terhadap pertumbuhan Streptococcus mutans.

\section{METODE}

\section{Jenis, Waktu dan Tempat Penelitian}

Jenis penelitian ini adalah bersifat eksperimen laboratorium dimana sampel ekstrak daun Wungu dibuat dalam beberapa konsentrasi 
yaitu 2\%, 3\%, 4\% dan 5\%, serta menggunakan Amoxisilin sebagai kontrol positif. Masing-masing konsentrasi dan kontrol diujikan terhadap pertumbuhan Streptococcus mutans. Penelitian ini telah dilakukan pada bulan Juli - September 2017. Lokasi pengambilan sampel yaitu Kabupaten Enrekang, dan lokasi penelitian dilakanakan di Laboratorium Bakteriologi Jurusan Analis Kesehatan Poltekkes Makassar.

\section{Populasi, Sampel, Alat dan Bahan}

Populasi dalam Penelitian ini adalah daun Wungu yang berasal dari Kabupaten Enrekang. Sampel dalam penelitian ini adalah ektrak daun Wungu yang berasal dari Kabupaten Enrekang. Alat - Alat yang digunakan Autoklaf, Bejana Maserasi, Erlenmeyer, Gelas ukur, Batang pengaduk, Cawan petri, Inkubator, Jangka sorong, Lampu Spritus, Ose bulat, Pinset, Pipet Volume, Pencadang, Sendok tanduk, Timbangan kasar, Timbangan analitik. Bahan-bahan yang digunakan Aquadest steril, aluminium foil, Amoksisillin, biakan murni Streptococcus mutans, Ekstrak etanol $70 \%$ daun Wungu (Graptophylum pictum Griff), Kapas lidi steril (swab steril), Etanol 70\%, Medium Muller Hinton Agar (MHA), Medium Nutrien Agar (NA), $\mathrm{NaCl}$ fisiologis 0,9\%, Na. CMC $1 \%$.

\section{Prosedur Kerja}

Pengolahan Bahan Uji

Daun tanaman Wungu yang telah dikumpulkan, dibersihkan dari kotoran yang melekat kemudian dicuci dengan air mengalir. Setelah itu sampel yang telah dibersihkan kemudian diangin- anginkan tanpa menggunakan sinar matahari langsung hingga kering selanjutnya di potong kecil-kecil hingga berupa simplisia.

Pembuatan Ekstrak Etanol:

Daun tanaman wungu yang sudah berupa simplisia diekstraksi dengan menggunakan metode maserasi dengan cara ditimbang sebanyak 500 gram kemudian di masukkan ke dalam bejana maserasi lalu diberi cairan penyari etanol $70 \%$ secukupnya pada wadah kaca dengan perbandingan bahan dan pelarut adalah $1: 5 \mathrm{~b} / \mathrm{v}$ kemudian ditutup dan disimpan pada tempat yang terlindung dari cahaya matahari langsung, sambil berulang-ulang diaduk. Setelah 5 hari sampel tersebut disaring, ampasnya di masukkan kembali ke dalam bejana maserasi dan dilakukan seperti semula, maserasi dilakukan 3 x 5 hari. Filtrat yang diperoleh kemudian dirotavavor hingga diperoleh ekstrak kental etanol $70 \%$. Ekstrak etanol $70 \%$ daun wungu kemudian disimpan di dalam lemari pendingin pada suhu $10^{\circ} \mathrm{C}$.

Penyiapan Kultur Murni Mikroba Uji Peremajaan Kultur Mikroba Uji:

Medium Nutrien Agar (NA) yang telah dibuat dimasukkan kedalam tabung-tabung reaksi lalu dimiringkan, setelah medium Nutrient Agar (NA) memadat, diambil 1 ose isolat mikroba uji dengan menggunakan ose bulat steril kemudian digoreskan pada permukaan medium nutrient agar (NA) lalu inkubasi pada inkubator pada suhu $37^{\circ} \mathrm{C}$ selama 24 jam. Pembuatan Suspensi Mikroba Uji:

Bakteri uji yang berumur 24 jam diambil sebanyak 1 ose dan dilarutkan ke dalam larutan fisiologis $\mathrm{NaCl} \quad 0,9 \%$ steril. Kekeruhan 
Jurnal Media Analis Kesehatan, Vol. 8, No.2, November 2017

http://journal.poltekkes-mks.ac.id/ojs2/index.php/mediaanalis

e-ISSN : 2621-9557

p-ISSN : 2087-1333

dibandingkan dengan standar kekeruhan Mac Farland 0,5.

Pengujian Ekstrak Etanol Daun Wungu Terhadap Bakteri Uji Streptococcus mutans.

Medium MHA dicairkan pada suhu $45^{\circ}$ C. Diambil $15 \mathrm{ml}$ dan $\pm 0,2$ $\mathrm{ml}$ suspensi bakteri lalu dituang ke dalam cawan petri secara aseptik dan dibiarkan memadat. Setelah memadat kemudian dipasang paperdisk yang telah dicelupakan kedalam sampel sesuai konsentrasi yakni $2 \%, \# \%, 4 \%$ dan 5\% serta kontrol positif (amoxicillin) dan kontrol negatif (Na. CMC 1\%) kemudian diatur jaraknya sedemikian rupa dalam cawan petri. Inkubasi dalam inkubator pada suhu $37^{\circ} \mathrm{C}$ selama 1 x 24 jam. Di ukur diameter zona hambatan yang terbentuk. Pengamatan dan Pengukuran Diameter Hambatan: Pengamatan dan pengukuran diameter hambatan dilakukan setelah masa inkubasi 1 x 24 jam pada suhu $37^{\circ} \mathrm{C}$ dalam inkubator dengan menggunakan mistar geser.

Tabel 1. Hasil pengukuran diameter hambatan $(\mathrm{mm})$ uji efek antibakteri ekstrak daun Wungu Asal Kabupaten Enrekang terhadap pertumbuhan Streptococcus mutans masa inkubasi $1 \times 24$ jam pada suhu $37^{\circ} \mathrm{C}$.

\begin{tabular}{|c|c|c|c|c|c|c|c|}
\hline \multirow[t]{2}{*}{ Bakteri Uji } & \multirow[t]{2}{*}{$\begin{array}{c}\text { Masa } \\
\text { Inkubasi }\end{array}$} & \multicolumn{6}{|c|}{$\begin{array}{c}\text { Diameter Zona Hambatan (mm) } \\
\text { Ekstrak Etanol 70\% Daun Wungu }\end{array}$} \\
\hline & & $2 \%$ & $3 \%$ & $4 \%$ & $5 \%$ & Kontrol (+) & Kontrol (-) \\
\hline $\begin{array}{l}\text { Streptococc } \\
\text { us mutans }\end{array}$ & $1 \times 24$ jam & $\begin{array}{l}12,32 \\
12,45 \\
13,05\end{array}$ & $\begin{array}{l}13,10 \\
13,97 \\
14,12\end{array}$ & $\begin{array}{l}14,36 \\
14,76 \\
15,36\end{array}$ & $\begin{array}{l}15,05 \\
16,37 \\
16,89\end{array}$ & $\begin{array}{l}17,31 \\
17,37 \\
18,42\end{array}$ & $\begin{array}{l}0 \\
0 \\
0\end{array}$ \\
\hline Jum & & 37,82 & 41,19 & 44,48 & 48,31 & 53,10 & 0 \\
\hline Rata & & 12,60 & 13,73 & 14,82 & 16,10 & 17,70 & 0 \\
\hline
\end{tabular}

Data Primer September 2017

\begin{abstract}
Analisa Data
Data diambil dari hasil pengamatan dan hasil pengukuran sampel uji. Data dianalisa secara statistik dengan menggunakan metode analysis of varian (Anova) untuk melihat pengaruh sediaan ekstrak etanol $70 \%$ daun wungu dengan berbagai variasi konsentrasi terhadap hambatan pertumbuhan yang dihasilkan.
\end{abstract}

\section{HASIL}

Hasil penelitian berupa diameter zona hambatan terhadap uji efek antibakteri ekstrak daun Wungu (Graptophylum pictum Griff) terhadap pertumbuhan Streptococcus mutans masa inkubasi 1 x 24 jam pada suhu $37^{0}$ C. Hasil penelitian selengkapnya dapat dilihat pada tabel berikut :

\section{PEMBAHASAN}

Pada penelitian ini dilakukan dengan tujuan untuk menguji efek antibakteri ekstrak Daun Wungu asal Kabupaten Enrekang dalam

menghambat

pertumbuhan

Streptococcus mutans. Penggunaaan bahan herbal memiliki keuntungan yaitu mudah didapat, murah, aman, tidak membahayakan lingkungan sekitar. Salah satu bahan herbal yang
} 
Jurnal Media Analis Kesehatan, Vol. 8, No.2, November 2017

http://journal.poltekkes-mks.ac.id/ojs2/index.php/mediaanalis

e-ISSN : 2621-9557

p-ISSN : 2087-1333

terdapat di Kabupaten Enrekang memiliki sifat antibakteri yaitu daun wungu. Daun wungu dilaporkan mengandung tanin, alkaloid sitosterol, glikosid, flavonoid, steroid, saponin, kalsium oksalat dan asam format. Berbagai kandungan kimiawi yang terkandung dalam daun wungu mempunyai sifat sebagai obat wasir, laksatif lemah diuretik ringan. Pengobatan tradisional daun wungu juga digunakan untuk pengobatan terhadap luka, bengkak, borok, bisul, penyakit kulit, secara eksperimental ekstrak daun wungu berkhasiat menghambat pembengkakan dan menurunkan permiabilitas vaskular, antiplak gigi / karies gigi, antiinflamasi.

Sampel daun Wungu yang diperoleh dari Kabupaten Enrekang yang digunakan dalam penelitian ini terlebih dahulu dikumpulkan, dibersihkan dari segala kotoran yang melekat kemudian dicuci dengan air mengalir. Sampel yang telah dibersihkan kemudian dikeringkan dengan jalann diangin- anginkan tanpa menggunakan sinar matahari langsung hingga kering selanjutnya di potong kecil - kecil hingga berupa simplisia. Sampel daun wungu yang sudah dikeringkan diekstraksi dengan menggunakan metode maserasi dengan cara ditimbang sebanyak 500 gram kemudian di masukkan ke dalam bejana maserasi lalu diberi cairan penyari etanol $70 \%$ secukupnya pada wadah kaca dengan perbandingan bahan dan pelarut adalah $1: 5 \mathrm{~b} / \mathrm{v}$ kemudian ditutup dan disimpan pada tempat yang terlindung dari cahaya matahari langsung, sambil berulang-ulang diaduk. Setelah 5 hari sampel tersebut disaring, filtrat yang diperoleh, kemudian dirotavavor hingga diperoleh ekstrak kental.

Ekstrak etanol 70\% daun wungu disimpan didalam lemari pendingin pada suhu $10^{\circ} \mathrm{C}$. Setelah itu dibuat beberapa konsentrasi suspensi menggunakan Na.CMC $1 \%$ yakni $2 \%$ $\mathrm{b} / \mathrm{v}, 3 \% \mathrm{~b} / \mathrm{v}, 4 \% \mathrm{~b} / \mathrm{v}$ dan $5 \%$ b/v kemudian diujikan terhadap Streptococcus mutans untuk mendapatkan efek antibakteri dari pengaruh pemberian ekstrak etanol $70 \%$ daun wungu dengan pembanding kontrol positif yaitu Amoksisilin dengan konsentrasi 30 bpj dan kontrol negatif yaitu menggunakan larutan Na. CMC $1 \%$.

Hasil penelitian yang telah dilakukan selama $1 \quad x \quad 24$ jam didapatkan hasil yakni untuk hasil pengukuran diameter hambatan ( $\mathrm{mm}$ ) ui efek antibakteri ekstrak daun Wungu terhadap pertumbuhan Streptococcus mutans yakni dengan rata -rata zona hambatan yakni untuk $2 \%$ yaitu $12,60 \mathrm{~mm}, 3 \%$ yaitu 13,73 $\mathrm{mm}, 4 \%$ yaitu $14,82 \mathrm{~mm}$ dan untuk $5 \%$ yaitu $16,10 \mathrm{~mm}$. Untuk pembanding kontrol positif didapatkan sebesar $17,70 \mathrm{~mm}$ dan kontrol negatif didapatkan $0 \mathrm{~mm}$, dari hasil tersebut dapat diketahui bahwa pengaruh pemberian ekstrak etanol $70 \%$ daun Wungu memiliki kemampuan yang efektif dalam menghambat pertumbuhan Streptococcus mutans. Ini dikarenakan komponen kimia yang terdapat pada daun wungu meliputi alkaloid, glikosida, steroid, saponin, tanin yang dapat berfungsi sebagai senyawa aktif yang dapat menghambat pertumbuhan mikroorganisme.

Hasil tersebut dapat dilihat pada uji statistik Rancangan Acak Lengkap 
Jurnal Media Analis Kesehatan, Vol. 8, No.2, November 2017

http://journal.poltekkes-mks.ac.id/ojs2/index.php/mediaanalis

e-ISSN : 2621-9557

p-ISSN : 2087-1333

antara perlakuan $2 \%, 3 \%, 4 \%$ dan $5 \%$ dalam menghambat pertumbuhan Streptococcus mutans berbeda nyata (signifikan), dimana $\mathrm{Fh}=366,20$ lebih besar dari pada Ft untuk 0,05 = 3,11 dan $0,01=5,06$. Hasil analisis varians (ANAVA) menunjukkan $\mathrm{H}_{0}$ ditolak pada taraf $\alpha=0,05$ dan 0,01 .

Pada kontrol positif sebagai pembanding digunakan antibiotik amoksisilin karena dimana kita ketahui amoksisilin adalah antibiotik golongan betalaktam termasuk keluarga penisillinum yang mempunyai spektrum sedang, aktif terhadap bakteri gram negatif maupun gram positif. Amoksisilin (Amoxicillin) adalah bakteriolitik yang bekerja dengan cara menghambat sintesis dinding sel bakteri sehingga lintas hubungan antara rantai polimer peptidoglikan linier yang membentuk komponen utama dari dinding sel bakteri menjadi terganggu.

Hasil dari penelitian ini dapat diketahui bahwa uji efek antibakteri ekstrak daun Wungu memiliki kemampuan sebagai antibakteri dan efektif dalam menghambat pertumbuhan Streptococcus mutans. Ini dapat dilihat dari berbagai konsentrasi yang diujikan yang ditandai dengan adanya zona hambatan yang terbentuk pada pengujian dari bakteri tersebut serta adanya berbagai acuan dan literatur pendukung tentang daun Wungu (Graptophylum pictum Griff) sebagai tanaman yang bersifat sebagai antibakteri.

\section{KESIMPULAN}

Berdasarkan hasil penelitian dan pembahasan, maka dapat ditarik kesimpulan sebagai berikut bahwa
Ekstrak daun Wungu asal Kabupaten Enrekang memiliki kemampuan sebagai antibakteri dan efektif dalam menghambat pertumbuhan Streptococcus mutans. Hasil uji statistik memperlihatkan adanya perbedaan yang nyata antara perlakuan dalam menghambat pertumbuhan Streptococcus mutans, dimana $\mathrm{Fh}=366,20$ lebih $>\mathrm{Ft}$ untuk $0,05=3,11$ dan $0,01=5,06$.

\section{SARAN}

Disarankan peneliti selanjutnya untuk meneliti lebih lanjut tentang efektifitas dari ekstrak batang tanaman Wungu

\section{DAFTAR PUSTAKA}

Andre T.W., 2014, Antibakteri, Artikel Kesehatan, Cakupan Kerja Obat Antibakteri, Diakses tanggal 01 April 2016.

Bronckers,A.L.JJ,D.M. Lyaruu, P.K. Denbesten, 2009, The Impact of Fluoride on Ameloblasts and the Mechanisms of Enamel Fluorosis, US National Library of Medicine National Institutes of Health, J Dent Res. 2009 Oct; 88(10): 877-893.

Departemen Kesehatan Republik Indoneasia., 1979, Farmakope Indonesia, Edisi IV, Jakarta.

Departemen Kesehatan Republik Indonesia, 1986, Sediaan Galenik, Direktorat Jenderal Pengawasan Obat dan Makanan, Jakarta

Djide.N, 2003 Mikrobiologi

Farmasi, Universitas Hasanuddin, Makassar. 
Jurnal Media Analis Kesehatan, Vol. 8, No.2, November 2017 http://journal.poltekkes-mks.ac.id/ojs2/index.php/mediaanalis

Dwidjoseputro,

D.,1998.

Mikrobiologi.

Djambatan. Jakarta.

Dwidjoseputro. 2005. Dasar-dasar Mikrobiologi. Percetakan Imagraph. Jakarta .

Gembong

2010. Taksonomi Tumbuhan

(Spermatophyta),

Gajah Mada University Press, Yogyakarta.

Lakare, Ch., 2002. Mikrobiologi Kedokteran I. Bagian Mikrobiologi Kedokteran FK Universitas Hasanuddin. Makassar.

Nugraha, Ari Widya. 2008. Streptococcus mutans: Si Plak Dimana - mana (Online), (http://www.usd.com diakses 15 April 2016)

Iftitah, Lailatul. 2005. Uji Daya Hambat dan Analisis KLTBioautografi Ekstrak Biji Jintan Hitam (Nigalla sativa L.) Terhadap Bakteri Streptococcus mutans. Skripsi tidak diterbitkan. Makassar: Program Strata 1. MIPA. UNHAS

Hariana, A. 2009. Tumbuhan Obat dan Khasiatnya Seri 1. Penebar Swadaya. $158 \mathrm{hlm}$

Herijulianti, E., Nurjanah, N., Putri M. H., 2010, Ilmu Pencegahan Penyakit Jaringan Keras dan Jaringan Pendukung Gigi. 1st ed. Jakarta:EGC.

Jawetz, Melnick, \& Adelberg. 1996. Mikrobiologi Kedokteran.
EGC Penerbit Buku

Kedokteran. Jakarta. Hal 218

Pelczar M., 2005, Dasar-Dasar Mikrobiologi, Jilid I, Universitas Indonesia, Jakarta.

Puspati S., 2013, Manfaat Handeuleum dan semua Khasiat Daun Ungu, http://herbalobat.blogspot.co $\mathrm{m} / \mathrm{p} /$ request-artikel.html diakses tanggal 15 April 2015 Sumarny R., 2013, Efek Antiinflamasi dan Anti-diare Ekstrak Etanol Herba Meniran (phyllanthus niruri l.) dan Daun Ungu (garptophyllum pictum $l$. Griff), Prosiding Seminar Nasional Perkembangan Terkini Sains Farmasi dan Klinik III 2013, Fakultas Farmasi Universitas Pancasila Sylvia T. Pratiwi, 2008, Mikrobiologi Farmasi, Penerbit Erlangga, Bandung.

Tracy J.W. dan Webster L.T., 2008, In : Goodman \& Gilman Dasar Farmakologi Terapi; Volume 2, Edisi 10 (Hanif et.al, penerjemah), Penerbit Buku Kedokteran EGC, Jakarta.

Waluyo L., 2008, Teknik Metode Dasar Mikrobiologi, Penerbit UMM Press, Malang.

Wijayakusuma, H.M., S. Dalimartha, dan A.S. Wirian. 1996. Tanaman Berkhasiat Obat di Indonesia. Jilid 4.. Pustaka Kartini. 166 hlm. 